\title{
A Study to Assess Prevalence and Drug Utilization Pattern in Hepatic Impairment Patients with or without Comorbidities in a Tertiary Care Teaching Hospital
}

\author{
Stephy Babu, Sethulekshmi Sadanandan, Rajnarayan Prasad Patel, Santosh Uttangi* \\ Department of Pharmacy Practice, SCS College of Pharmacy, Harapanahalli, Karnataka, INDIA.
}

\begin{abstract}
Background: The liver is the core of metabolic activity in the body. Around $50 \%$ of the classes of drugs are known to be hepatotoxic. Thus prescribing medications in patients with liver disease is indeed a challenging task. Objectives: To study the prevalence and to carry out the drug utilization evaluation of the therapy prescribed among hepatic impairment patients. Methodology: A prospective observational study was carried out for six months among inpatients of the medicine department of Chigateri district hospital. Patients were enrolled on the basis of inclusion criteria; data was collected using a data collection form and results were analyzed using MS Excel. Results: A total of 160 patients were enrolled, the most prevalent condition was alcoholic liver disease $(n=66,41.25 \%)$ followed by chronic liver disease $(n=47,29.38 \%)$ and hepatic encephalopathy $(n=12,7.5 \%)$. Out of 1466 drugs been prescribed, 795 drugs were used specifically for hepatic impairment. Drugs used to treat oedema (diuretics) were most
\end{abstract}

commonly prescribed ( $n=198,25 \%)$ followed by gall stone dissolution agents $(n=124,16 \%)$ and sugars $(n=97,12 \%)$. Conclusion: Alcoholic liver disease was the most prevalent hepatic condition, followed by chronic liver disease. The diuretics were the most widely used hepato-specific drugs among the patients.

Key words: Drug utilization pattern, Hepatic impairment, Abstinence, Diuretics.

\section{Correspondence}

Dr. Santosh Uttangi

Department of Pharmacy Practice, SCS College of Pharmacy, Harapanahalli-583131, Karnataka, INDIA.

Email: santoshuttangi05@gmail.com

DOI: 10.5530/jyp.2021.13.34

\section{INTRODUCTION}

Chronic Liver Disease (CLD) is an umbrella term for the disease of the liver that occurs due to prolonged exposure to various immunological, mechanical, or metabolic injury for six or more months without complete subsiding or termination of the abnormal disease condition. ${ }^{1}$ According to the European Association for the Study of the Liver, approximately two million deaths per year worldwide are due to liver diseases, and one million are due to cirrhosis, viral hepatitis and hepatocellular carcinoma. ${ }^{2}$ As $50 \%$ of the class of drugs in physician's desks are known to be hepatotoxic, prescribing medications in patients with liver disease is indeed a challenging task. ${ }^{3}$ Drug utilization studies are significant for obtaining information about the patterns of drug use, quality, characteristics and the results of drug use. ${ }^{4-6}$ These studies can help in understanding the drug prescribing and utilization trends in the institution and allow to get a better insight into the therapy. ${ }^{7}$ Prescription pattern and drug evaluation studies are even more important as the majority of drugs are metabolized in the liver. ${ }^{1}$ Majority of liver diseases mostly originated from alcohol abuse, obesity and longterm administration of various hepatotoxic drugs like anti-epileptics, anti-tuberculosis and antiretroviral drugs. ${ }^{2}$ Thus, the patient needs the safest and effective therapy with proper patient counselling and dosage adjustment while the administration is at its peak. The clinical pharmacist can educate the patient regarding the safe use of medicine after knowing the trends in the hospital. ${ }^{8}$ Hence, the purpose of this prospective study is to find out the most prevalent type of hepatic impairment and assess the drug utilization pattern among hepatic impairment patients.

\section{MATERIALS AND METHODS}

Study site, design and duration: This was an observational and prospective study conducted in the medicine department of Chigateri District Hospital, Davangere (Tertiary care teaching hospital) for a period of six months from November 2019 to April 2020.

Sample size: Proposed sample size was calculated by using the formulae, Sample Size $=\frac{Z_{1-\alpha / 2}{ }^{2} \times p(1-p)}{d^{2}}$

Where,

$Z_{1-\alpha / 2}=$ standard normal variant (at $5 \%$ type $\mathrm{i}$ error $(p<0.05)$, it is 1.96)

$\mathrm{P}=$ expected proportion in the population-based on previous studies.

$\mathrm{D}=$ absolute error

Prevalence (p) was found to be $11 \%{ }^{9}$. So, taking this value, we got:

Sample Size $=\frac{1.96^{2} \times 0.11(1-0.11)}{0.05^{2}}$

$=150.43$

So, a minimum required sample size was 151 patients, 160 was the achieved sample size.

Study criteria: Inpatients of the general medicine ward of either sex above 18 years of age and diagnosed with any type of hepatic diseases with or without comorbidities were enrolled in the study. Patients who were pregnant or having a terminal illness or whose complete information was missing were excluded from the study. Informed consent was taken from enrolled patient. 
Study procedure: Patients were enrolled based on the inclusion and exclusion criteria by obtaining consent from each. All the relevant data was entered into a well-designed data collection form. The collected data were analysed for further investigation on prescribing trends in hepatic impairment of the patients admitted in the medicine department and also to study the most prevalent type of hepatic impairment among the study patients. Data were analysed using Microsoft Excel (descriptive analysis) and results were presented in graphs and tables.

\section{RESULTS}

\section{Age and Gender-Wise Distribution of Study Population}

In our study, the age group between which there were most hospital admissions was 31-40 $(n=51,32 \%)$ among males and 41-50 $(n=5,3 \%)$ among females followed by 41-50 $(n=39,24 \%)$ in males and 51-60 $(n=4$, $2.5 \%)$ in females. The complete information is depicted in Table 1.

\section{Prevalence of Various Liver Impairments}

Out of a total of 160 patients, the most prevalent hepatic impairment was alcoholic liver disease $(n=66,41.25 \%)$ and chronic liver disease $(n=47$, $29.38 \%)$ followed by hepatic encephalopathy $(n=12,7.5 \%)$, and the least common were alcoholic hepatitis $(n=4,2.5 \%)$, drug induced hepatitis $(n=4,2.5 \%)$ and cholelithiasis $(n=4,2.5 \%)$. The details are shown in Table 2

\section{Occurrences of Comorbidities among Hepatic Impairment Patients:}

Patients being admitted with hepatic impairment may or may not be present with comorbidities. They have been categorized based on the presence or absence of comorbidities and the number of comorbid illnesses. Out of 160 patients, $(n=98,61.25 \%)$ of hepatic patients were with comorbid illness, whereas $(n=62,38.75 \%)$ of them were without comorbidities. Among patients having comorbid conditions, hepatic patients with one comorbidity accounted for $(n=69,43.12 \%)$, and two comorbidities accounted for $(n=29,18.12 \%)$ of the total hepatic impairment patients. The details are shown in Table 3.

\section{Distribution on the Basis of Child-Pugh and Discriminant Score}

Based on the Child-Pugh score, $(n=20,12.5 \%)$ of the 160 patients were observed to be underclass A, $(n=103,64.38 \%)$ as class B, and $(n=37$, $23.13 \%)$ as class $\mathrm{C}$ and based on discriminant score, $(n=117,73.13 \%)$ of the total cases showed good prognosis and $(n=43,26.88 \%)$ showed poor diagnosis.

Table 1: Age and Gender Wise Distribution.

\begin{tabular}{ccccc}
\multirow{2}{*}{ S. no } & \multirow{2}{*}{ Age group } & \multicolumn{2}{c}{ Gender } & \multirow{2}{*}{ Total no of patients, } \\
\cline { 3 - 4 } & & Male, $\mathbf{n}(\%)$ & Female, $\mathbf{n}(\%)$ & $3(2 \%)$ \\
\hline 1 & $<20$ & $3(2 \%)$ & $0(0 \%)$ & $20(12 \%)$ \\
2 & $21-30$ & $18(11 \%)$ & $2(1 \%)$ & $53(33 \%)$ \\
3 & $31-40$ & $51(32 \%)$ & $2(1 \%)$ & $44(28 \%)$ \\
4 & $41-50$ & $39(24 \%)$ & $5(3 \%)$ & $28(18 \%)$ \\
5 & $51-60$ & $24(15 \%)$ & $4(3 \%)$ & $7(4 \%)$ \\
6 & $61-70$ & $7(4 \%)$ & $0(0 \%)$ & $3(2 \%)$ \\
7 & $71-80$ & $3(2 \%)$ & $0(0 \%)$ & $2(1 \%)$ \\
8 & $>80$ & $1(1 \%)$ & $1(1 \%)$ & $\mathrm{N}=160(100 \%)$ \\
\hline
\end{tabular}

\section{Drug Utilization Pattern of Drugs Being Used Specifically} for Hepatic Impairment

Out of 1466 drugs been prescribed, 795 drugs were used specifically for hepatic impairment. Drugs used to treat oedema (diuretics) were most commonly prescribed $(n=198,25 \%)$ followed by gall stone dissolution agents $(n=124,16 \%)$ and sugars $(n=97,12 \%)$ and the least prescribed was anti-viral drugs $(n=1,0.1 \%)$ as shown in Table 4 .

\section{Drug Utilization Pattern of Non-Hepatospecific Drugs}

Among 1466 drugs been prescribed, 671 drugs were non-hepatospecific. The most commonly used class of drug is antibiotics $(n=164,24 \%)$, followed by antiulcer agents $(n=158,24 \%)$ and vitamin supplements $(n=111,16.5 \%)$ and the least prescribed were corticosteroids and antiviral $(n=2,0.30 \%)$ as illustrated in Table 5.

\section{Most Commonly Observed Drug-Related Problems and Medication Errors}

Out of 160 prescriptions, 36 prescriptions showed various types of drugrelated problems, out of which indication without drugs ranks the most $(n=25,62.5 \%)$ followed by drugs without indication $(n=6,15 \%)$ and the least observed was inappropriate medication $(n=5,12.5 \%)$.

\section{DISCUSSION}

Hepatic impairment can be predisposed by many factors. One of the major is alcohol abuse. Alcohol abuse is now becoming the leading cause of morbidity and mortality and also has become one among the socioeconomic burden. ${ }^{9}$ In the study majority of the patients being admitted among males were between age group $31-40$ years $(n=51,32 \%)$ and among females were between $41-50$ years $(n=5,3 \%)$ in contrast to results found in Mangalagiri, Guntur. ${ }^{10}$ where 51-60 years were predominant among males $(n=26)$. In this study, the most prevalent hepatic impairment observed in the six months study was alcoholic liver disease $(n=66,41 \%)$ due to the excessive consumption of alcohol among individuals, but it doesn't coincide with the study conducted at Nigeria, where hepatocellular carcinoma $(n=289,44.3 \%)$ was prevalent. ${ }^{11}$ In this study, both one and two comorbidities were observed; portal hypertension was the most occurring comorbidity (10\%), which is similar to the study conducted at Andhra Pradesh ( $n=5,30.35 \%)$, but in contrast hypothyroidism in a study conducted at Mangalagiri Guntur $(n=6,27.7 \%) .{ }^{9,10}$ In this study, patients falling in class B of ChildPugh Score is most observed ( $n=103,64.38 \%$ ), this may be due to the earlier hospital admissions due to the emergence of various clinical manifestations in contrast to the study conducted at Kochi, Kerala

Table 2: Prevalence of Various Liver Impairments.

\begin{tabular}{ccc}
\hline S. no & Diseases & No. of patients, $\mathbf{n}(\%)$ \\
\hline 1 & Alcoholic liver disease & $66(41 \%)$ \\
2 & Chronic liver disease & $47(29 \%)$ \\
3 & Hepatic encephalopathy & $12(8 \%)$ \\
4 & Pancreatitis & $11(7.5 \%)$ \\
5 & Non-alcoholic hepatitis & $7(4 \%)$ \\
6 & Hepatocellular carcinoma & $5(3 \%)$ \\
7 & Alcoholic hepatitis & $4(2.5 \%)$ \\
8 & Drug-induced hepatitis & $4(2.5 \%)$ \\
9 & Cholelithiasis & $4(2.5 \%)$ \\
& Total & $\mathrm{N}=160(100 \%)$ \\
\hline
\end{tabular}


Table 3: Occurrences of Comorbidities among Hepatic Impairment Patients.

\begin{tabular}{|c|c|c|c|c|}
\hline \multirow{3}{*}{$\begin{array}{c}\text { Hepatic diseases } \\
\text { Chronic liver } \\
\text { disease }\end{array}$} & \multicolumn{2}{|c|}{ One comorbidity, n (\%) } & \multicolumn{2}{|c|}{ Two comorbidities, n (\%) } \\
\hline & CLD+Anaemia & $6(3.75)$ & $\mathrm{CLD}+\mathrm{HE}+\mathrm{PH}$ & $2(1.25)$ \\
\hline & $\mathrm{CLD}+\mathrm{HE}$ & $3(1.9)$ & $\mathrm{CLD}+\mathrm{PH}+$ Cystitis & $1(0.63)$ \\
\hline & $\mathrm{CLD}+\mathrm{CKD}$ & $3(1.9)$ & $\mathrm{CLD}+\mathrm{HTN}+\mathrm{T} 2 \mathrm{DM}$ & $1(0.63)$ \\
\hline & $\mathrm{CLD}+\mathrm{PH}$ & $16(10)$ & CLD+HRS+Anaemia & $2(1.25)$ \\
\hline & CLD+Bronchitis & $1(0.63)$ & Total & $6(3.76)$ \\
\hline & CLD+T2DM & $2(1.25)$ & & \\
\hline & Total & $31(19.43)$ & & \\
\hline \multirow{11}{*}{$\begin{array}{l}\text { Alcoholic liver } \\
\text { disease }\end{array}$} & ALD+Pancreatitis & $4(2.5)$ & $\mathrm{ALD}+\mathrm{HCC}+\mathrm{HBV}$ & $1(0.63)$ \\
\hline & ALD+Anaemia & $14(8.75)$ & $\mathrm{ALD}+\mathrm{HE}+$ Anaemia & $4(2.5)$ \\
\hline & $\mathrm{ALD}+\mathrm{CKD}$ & $2(1.25)$ & $\mathrm{ALD}+\mathrm{HE}+\mathrm{PH}$ & $4(2.5)$ \\
\hline & $\mathrm{ALD}+\mathrm{RVD}$ & $1(0.63)$ & $\mathrm{ALD}+\mathrm{PH}+$ Anaemia & $5(3.13)$ \\
\hline & ALD+HTN & $1(0.63)$ & Total & $10(8.76)$ \\
\hline & $\mathrm{ALD}+\mathrm{PH}$ & $7(4.38)$ & & \\
\hline & $\mathrm{ALD}+$ Gastritis & $2(1.25)$ & & \\
\hline & ALD+Psoriasis & $1(0.63)$ & & \\
\hline & ALD+cellulitis & $1(0.63)$ & & \\
\hline & $\mathrm{ALD}+\mathrm{TB}$ & $1(0.63)$ & & \\
\hline & Total & $34(21.28)$ & & \\
\hline \multirow{3}{*}{$\begin{array}{l}\text { Hepatocellular } \\
\text { carcinoma }\end{array}$} & $\mathrm{HCC}+\mathrm{PH}$ & $1(0.63)$ & & \\
\hline & $\mathrm{HCC}+$ Anaemia & $1(0.63)$ & & \\
\hline & Total & $2(1.26)$ & & \\
\hline \multirow[t]{2}{*}{ Cholelithiasis } & Cholelithiasis+Anaemia & $2(1.25)$ & & \\
\hline & Total & $2(1.25)$ & & \\
\hline \multirow{3}{*}{$\begin{array}{l}\text { Drug induced } \\
\text { liver injury }\end{array}$} & & & $\mathrm{DILI}+\mathrm{TB}+\mathrm{RVD}$ & $3(1.88)$ \\
\hline & & & DILI+RVD+Anaemia & $1(0.63)$ \\
\hline & & & Total & $4(2.51)$ \\
\hline \multirow{3}{*}{$\begin{array}{l}\text { Alcoholic } \\
\text { hepatitis }\end{array}$} & & & $\mathrm{AH}+\mathrm{AGE}+$ Anaemia & $1(0.63)$ \\
\hline & & & $\mathrm{AH}+\mathrm{T} 2 \mathrm{DM}+\mathrm{PE}$ & $3(1.88)$ \\
\hline & & & Total & $4(2.51)$ \\
\hline \multirow[t]{2}{*}{ Total $[\mathrm{n}(\%)]$} & $69(43.12 \%)$ & & $29(18.12 \%)$ & $98(61.25)$ \\
\hline & \multicolumn{3}{|c|}{ Only hepatic diseases (without co-morbidities) [n (\%)] } & $62(38.75)$ \\
\hline Total & & & & $\mathrm{N}=160(100)$ \\
\hline
\end{tabular}

CLD: Chronic Liver Disease; ALD: Alcoholic Liver Disease; CKD: Chronic Kidney Disease; PH: Portal Hypertension; HE: Hepatic Encephalopathy; T2DM: Type 2 Diabetes Mellitus; HTN: Hypertension; HRS: HepatoRenal Syndrome; RVD: RetroViral Disease; TB: Tuberculosis; HCC: Hepato Cellular Carcinoma; AKI: Acute Kidney Injury; DILI: DrugInduced Liver Injury; AH: Alcoholic Hepatitis; AGE: Acute Gastro Enteritis; PE: Pleural Effusion

where class C (50\%) of Child-Pugh Score is most admitted as they are providing the reason that most are referred cases. ${ }^{12}$ In a Turkish study, patients scoring $\geq 32$ are considered as poor prognosis $(>50 \%)$ were observed to be more compared to $\leq 32$, which is regarded as a good prognosis. ${ }^{13}$ Whereas our study showed most patients in $\leq 32$, that is good prognosis category only $(n=117,73 \%)$. In a study conducted in Andhra Pradesh showed the drug utilization of diuretics preponderantly compared to other class of drugs $(n=220)$, which is similar to our study, 
Table 4: Drug Utilization Pattern of Drugs Used Specifically for Hepatic Impairment.

\begin{tabular}{ccc}
\hline Sl. no & Class of drugs & Number of drugs $\mathbf{n}(\%)$ \\
\hline 1 & Liver protectants & $70(9)$ \\
2 & Gall stone dissolution agents & $124(16)$ \\
3 & Sugars & $97(12)$ \\
4 & Laxatives & $9(1)$ \\
5 & Enzymes & $4(0.5)$ \\
6 & Drugs used to treat edema (diuretics) & $198(25)$ \\
7 & Drugs used to treat portal HTN & $59(7)$ \\
& ( $\beta$-blockers) & \\
8 & Antibiotics & $73(9)$ \\
9 & Anti-hemorrhagic agents & $83(10)$ \\
10 & Transfusions & $72(9)$ \\
11 & Corticosteroids & $5(1)$ \\
12 & Antivirals & $1(0.1)$ \\
& Total & $\mathrm{N}=795(100)$ \\
\hline
\end{tabular}

Table 5: Drug Utilization Pattern of Non-Hepatospecific Drugs.

\begin{tabular}{|c|c|c|}
\hline SI no & Class of drugs & Number of drugs $n(\%)$ \\
\hline 1 & Anti-ulcer drugs & $158(24)$ \\
\hline 2 & Analgesics & $42(6)$ \\
\hline 3 & Antibiotics & $164(24)$ \\
\hline 4 & Antiemetics & $39(6)$ \\
\hline 5 & Antidiarrheal & $12(2)$ \\
\hline 6 & Antihypertensive & $11(2)$ \\
\hline 7 & Cardiovascular Agents & $5(1)$ \\
\hline 8 & Antidiabetics & $5(1)$ \\
\hline 9 & Anti-convulsant & $23(3)$ \\
\hline 10 & Antivirals & $2(0.3)$ \\
\hline 11 & Vitamin Supplements & $111(16.5)$ \\
\hline 12 & Nebulisations & $8(1)$ \\
\hline 13 & Corticosteroids & $2(0.3)$ \\
\hline 14 & Antihistamines & $6(1)$ \\
\hline 15 & Miscellaneous & $48(7)$ \\
\hline \multirow[t]{2}{*}{16} & Transfusions & $35(5)$ \\
\hline & Total & $\mathrm{N}=671(100)$ \\
\hline
\end{tabular}

which showed utilization of diuretics like furosemide, spironolactone, amiloride and torsemide $(n=198,25 \%) .{ }^{9}$ This was in contrast with the other study conducted at Kochi, Kerala cholagogues $(92.66 \%)$ were prominent. ${ }^{12}$ In the study of drug utilization of non-hepatospecific drugs, antibiotics were prominently prescribed $(n=164,24 \%)$ similar to the study conducted at Andhra Pradesh $(n=188)$, in contrast, anti-ulcer drugs at Mangalagiri Guntur ( $n=175)$ were predominant. ${ }^{9,10}$ In a study conducted in Pakistan, the most commonly observed medication error was prescribing inappropriate medication $(n=48,49.48 \%) .{ }^{14}$ Whereas in our study, the most commonly observed medication error was indication without the drug $(n=25,62.5 \%)$, which is in contrast to their study. The study showed the incidence of drug-related problems and medication errors; this can be minimized by using the bagging system in the hospital pharmacy. ${ }^{15}$

\section{CONCLUSION}

In our study majority of males were found to be suffering from hepatic impairment more compared to females. The most prevalent hepatic impairment observed to be was alcoholic liver disease accompanied by portal hypertension. The utilization pattern of diuretics was more among hepatospecific drugs and antibiotics were utilized more among nonhepatospecific drugs. Patients mainly fell into class B of Child-Pugh Score compared to the other two classes (A and C) and based on Discriminant Score; good prognosis overweighed poor diagnosis. Our study suggests that there are fair chances to ameliorate the drug utilization pattern among the health care system and minimizing the unwanted use of various medications, especially antibiotics. Patient counseling can make a good impact on patients for abstinence from alcohol and preventing further harm to the liver.

\section{ACKNOWLEDGEMENT}

We authors want to thank the staff of SCS College of Pharmacy, Harapanahalli, for their support during the study.

\section{CONFLICT OF INTEREST}

The authors declare no conflict of interest.

\section{ABBREVIATIONS}

CLD: Chronic Liver Disease; ALD: Alcoholic Liver Disease; CKD: Chronic Kidney Disease; PH: Portal Hypertension; H\&E: Hepatic Encephalopathy; T2DM: Type 2 Diabetes Mellitus; HTN: Hypertension; HRS: HepatoRenal Syndrome; RVD: RetroViral Disease; TB: Tuberculosis; HCC: Hepato Cellular Carcinoma; AKI: Acute Kidney Injury; DILI: Drug-Induced Liver Injury; AH: Alcoholic Hepatitis; AGE: Acute Gastro Enteritis; PE: Pleural Effusion.

\section{REFERENCES}

1. Fauzi $A N$, Vishnupriya $V_{r}$ Gayathri R. Fatty liver disease: $A$ Review. Res J Pharm Tech. 2016;9(8):1263-7.

2. European Association for the Study of the Liver EASL Clinical Practice Guidelines: Drug-induced liver injury. J Hepat. 2019;70(1):1222-61.

3. Tandon KR. Prescribing in Patients with Liver Disease. Med Update. 2012;22(1):494-7.

4. Mohammed HAR, Babu N, Chand S, Nandakur UP, Bharathraj KC. Study on prescription pattern for osteoarthritis in a tertiary care teaching hospital: A retrospective study. Biomedicine. 2020;40(03):353-6.

5. Mehaneesha K, Rishab P, Seetharam SS, Mathias L, Chand S, Nandakumar UP, et al. A retrospective study on drug utilization pattern in management of rheumatoid arthritis. Res J Pharm Tech. 2020;13(11):5263-6.

6. Al-Jabri MM, Shastry CS, Chand S. Assessment of drug utilization pattern in chronic kidney disease patients in a tertiary care hospital-based on who core drug use indicators. J Global Pharm Tech. 2019;11(9):1-9.

7. Chandran BK, Vaddakan K, Altaf M, Shetty V, Chand S, Vijayan A, et al. A retrospective study on prospective usage pattern of analgesics in orthopaedics department of a tertiary care hospital. Int J Sci Tech Res. 2020;9(03):1207-11.

8. Voora L, Sah SK, Bhandari R, Shastry CS, Chand S, Rawal KB, Nandakumar UP, et al. Doctor of pharmacy: boon for healthcare system. Drug Invent Today. 2020;14(1):153-8.

9. Zeebaish S, Hemalatha P, Eswari PVSN, Kodandaraman T, Lakshmi P, Apoorva G. A Prospective Observational Study on Prescribing Patterns of Drugs Used in Alcoholic Liver Disease Patients at Tertiary Care Teaching Hospital. Int J Basic Clin Pharm. 2017;6(6):1386-92.

10. Kumar VS, Bhavana P, Supriya $\mathrm{CH}$, Rahaman SA. Prevalence and drug utilization pattern in hepatic impairment patients at a tertiary care hospital. Int J Sci Res. 2017;6(7):1878-83

11. Nwokediuko SC, Osuala PC, Uduma UV, Alaneme AK, Onwuka CC, Mesigo C. Pattern of liver disease admissions in a Nigerian tertiary hospital. Niger $\mathrm{J}$ Clin Pract. 2013;16(3):339-42.

12. Vijayan M, Anisha KA, Selina AS, Roshni PR. Clinical Profile and Prescribing 
Pattern of Cirrhosis in a Tertiary Care Hospital. Indian J Pharm Pract. 2014;7(3):69-74

13. Tekin F, Karasu Z, Erdogan El, Gunsar F, Ersoz G. A comparison of prognostic scoring systems in Turkish alcoholic hepatitis patients. J Gastrointest Dig Syst. 2016;6(6):1-6.
14. Shamim S, Shafique S. Evaluation of occurrence of medication errors in liver disease patients. J Adv Med Med Res. 2015;10(4):1-8.

15. Chand S, Shastry CS, Vinay BC, Bhandari R, Sah SK, Rawal KB. Brown, white, and blue bagging in special pharmacy: An emerging trend to minimize medication error. J Glob Pharm Technol. 2019;11(8):1-4.

Article History: Submission Date : 03-04-2021; Revised Date : 18-04-2021; Acceptance Date : 04-05-2021.

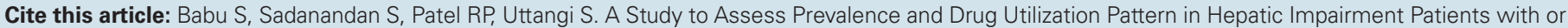
without Comorbidities in a Tertiary Care Teaching Hospital. J Young Pharm. 2021;13(2):167-71. 